Viso - Cadernos de estética aplicada Revista eletrônica de estética

ISSN 1981-4062

$N^{\circ} 15,2014$

http://www.revistaviso.com.br/

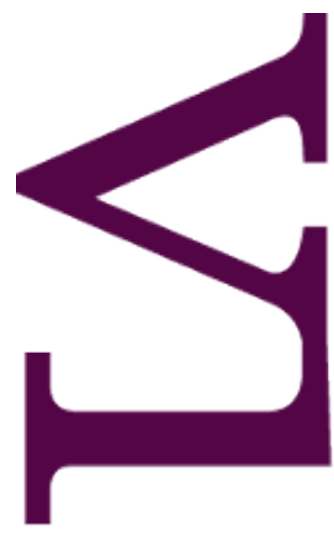

ᄂ

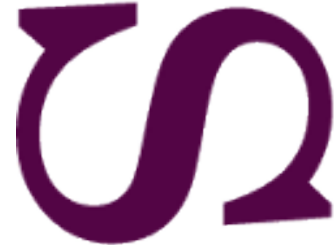

$\varangle$

4

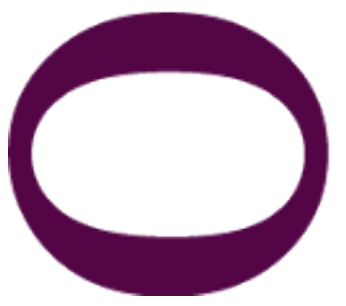

\title{
Uma paródia do mundo dos mortos Pedro Süssekind
}




\section{RESUMO}

Uma paródia do mundo dos mortos

Esse artigo é uma réplica ao texto de Pedro Caldas intitulado "A mosca e a panela: as formas da morte em A montanha mágica".

Palavras-chave: Thomas Mann - A montanha mágica - forma- morte

\section{ABSTRACT}

A Parody of the World of the Dead

This paper is a critical response to Pedro Caldas' "The Fly and the Pan: the Forms of Death in The Magic Mountain".

Keywords: Thomas Mann - The Magic Mountain - Form - Death 


\section{SÜSSEKIND, P. "Uma paródia do mundo dos mortos". In: Viso: Cadernos de estética aplicada, v. VIII, n. 15 (jan-dez/2014), pp. 121-126.}

DOI: 10.22409/1981-4062/v15i/179

Aprovado: 03.01.2015. Publicado: 31.01.2015.

(C) 2015 Pedro Süssekind. Esse documento é distribuído nos termos da licença Creative Commons Atribuição-NãoComercial 4.0 Internacional (CC-BY-NC), que permite, exceto para fins comerciais, copiar e redistribuir o material em qualquer formato ou meio, bem como remixá-lo, transformá-lo ou criar a partir dele, desde que seja dado o devido crédito e indicada a licença sob a qual ele foi originalmente publicado.

Licença: http://creativecommons.org/licenses/by-nc/4.0/deed.pt_BR

Accepted: 03.01.2015. Published: 31.01.2015.

(C) 2015 Pedro Süssekind. This document is distributed under the terms of a Creative Commons Attribution-NonCommercial 4.0 International license (CC-BY-NC) which allows, except for commercial purposes, to copy and redistribute the material in any medium or format and to remix, transform, and build upon the material, provided the original work is properly cited and states its license.

License: http://creativecommons.org/licenses/by-nc/4.0/ 
As formas da morte constituem um dos grandes temas clássicos da literatura, e isso desde as epopeias de Homero, com as descrições plásticas e precisas dos ferimentos mortais na guerra, a importância da morte gloriosa e a ida de Ulisses ao Hades. Pedro Caldas estuda, em seu texto "A mosca e a panela", como esse tema clássico da literatura foi elaborado por Thomas Mann em A montanha mágica.

Considerando o gênero do livro - um romance de formação -, o tema deve ser elaborado por Thomas Mann de maneiras diferentes, em diferentes pontos da história. Por isso, a estratégia da análise feita por Pedro Caldas é comparar as mortes de dois personagens, o avô e o primo do protagonista. A primeira é uma experiência da infância de Hans Castorp: a descrição do velório a que ele assistiu e de suas impressões a respeito da cerimônia e do cadáver. A segunda é uma experiência da vida adulta, que se passa no principal cenário do livro, o sanatório de Davos.

Ao explicitar e justificar seu tema, o texto recorre a um célebre ensaio de Thomas Mann, no qual ele afirma que o objeto de um romance de formação poderia ser "mostrar como a experiência de morte é, no final, uma experiência de vida" (p. 3). Portanto, a ideia é comentar passagens que indicam a relação da percepção da morte com a vida, e para isso são selecionados trechos do romance em que a morte é descrita segundo dois aspectos distintos: por um lado, o aspecto material, corpóreo, por outro o aspecto ideal, ou ritual, ou imagético. Basicamente o texto cita três passagens de $A$ montanha mágica, comenta essas passagens e recorre a algumas afirmações de Thomas Mann em seus ensaios ou diários, para relacionar os trechos de ficção com determinadas questões expressas teoricamente.

A comparação das passagens, chamando a atenção para os diversos aspectos da experiência da morte, parece ser "uma chave para compreender A montanha mágica", segundo as palavras de Pedro Caldas. E essa chave está ligada tanto ao conteúdo do livro (a conversão da experiência da morte em experiência de vida), quanto à sua forma, na qual se combinam o distanciamento irônico da narrativa e a sensorialidade das descrições.

As três passagens citadas são o velório do avô, o momento da morte do primo, Joachim, e a sessão espírita na qual Hans Castorp reencontra a imagem ou espectro de Joachim. Essas passagens são muito bem reproduzidas e comentadas no texto, por isso considero desnecessário voltar a elas no meu comentário. Destaco apenas a indicação dos detalhes algo inusitados que Pedro Caldas utiliza no título: a mosca que pousa no cadáver do avô e a panela na cabeça do espectro de Joachim. Esses dois elementos funcionam como recursos irônicos de distanciamento, sinais cômicos da finitude que se inscrevem nas cenas como que contra a vontade do personagem, marcando a experiência solene da morte com seu aspecto baixo e carnal.

O que me interessa aqui é ressaltar duas questões propriamente estéticas que se 
mostram no texto, no sentido de desenvolverem uma reflexão filosófica sobre a arte. A primeira questão diz respeito à pintura; a segunda diz respeito à poesia.

Pedro Caldas comenta, na descrição da cena do velório, a importância de uma pintura em tamanho natural, um retrato do avô em seu traje oficial de vereador. Thomas Mann apresentaria, por meio da contraposição entre o cadáver e o quadro, a ideia de uma ambivalência da arte. Enquanto, para a criança, o corpo rígido e cor de cera no qual uma mosca vem pousar não pode ser o verdadeiro avô, mas sim um ex-avô, um invólucro vazio, é o quadro que mostra o avô verdadeiro, a imagem solene, oficial, do morto, em correspondência com a solenidade ritual da cerimônia do velório (o ataúde luxuoso, as flores, o candelabro).

Essa contraposição é retomada, em chave invertida, no caso do primo Joachim. Sua morte no sanatório é descrita como um breve trespasse, no qual o próprio corpo adquire o sentido solene e elevado antes presente no quadro. A barba espessa que Joachim tinha deixado crescer lhe dá um aspecto viril de soldado, e com isso uma beleza que o primo tímido e discreto, com aspecto juvenil, não tinha em vida.

Com essa segunda cena, evidencia-se o outro elemento artístico que está presente nas passagens analisadas. Pedro Caldas associa a morte de Joachim ao tema da "bela morte", recorrendo à expressão formulada por Vernant para pensar a morte gloriosa dos heróis épicos na obra de Homero. É importante ressaltar que essa analogia se baseia numa passagem do romance, citada oportunamente no texto: o comentário do erudito Settembrini sobre a visita de Hans Castorp ao sanatório, mesmo não estando doente. Ele estaria de passagem ali, "como Ulisses no reino das sombras", alguém que comete a audácia de descer até as profundezas onde os mortos (aqui os tuberculosos em tratamento) levam uma existência irreal e sem sentido.

Certamente é uma frase que explicita o caráter paródico da literatura de Thomas Mann, sua consciente reelaboração de temas literários da tradição. E Pedro Caldas desdobra essa analogia em duas considerações. A primeira consideração diz respeito à "bela morte" do primo, em contraposição à morte do avô. Pois, tal como as mortes dos guerreiros gregos pensadas por Vernant, a de Joachim se dá na flor da idade e é associada a um ato de coragem, um feito guerreiro. (Ele tinha abandonado o tratamento para participar de um exercício militar.) Mas esse aspecto solene diz respeito à experiência de Hans Castorp, descrita por Thomas Mann. A descrição é quase a de um quadro no qual se retrata a comovente cena de morte do soldado. É assim que Hans chora a morte de seu primo jovem. Contudo, o autor insere uma ironia ao final da descrição, já que o choro leva a uma consideração poética sobre as lágrimas. Retomo trecho citado:

esse líquido claro, que corre neste mundo a toda hora e em toda a parte com tanta abundância e amargura que os poetas deram ao vale terreno um nome poético que 
lembra esse produto alcalino e salgado de glândulas, que o abalo dos nervos, causado por uma dor penetrante, arranca ao nosso corpo, e que, como Hans Castorp sabia, continha igualmente um pouco de mucina e albumina.

O recurso narrativo aqui está ligado à utilização do discurso indireto livre. A meu ver, podemos atribuir ao personagem Hans Castorp a divagação poética sobre suas próprias lágrimas, que termina (e o autor faz questão de mostrar isso voltando a um discurso direto no final) com essa estranha observação científica, distanciada. A ironia revela aqui uma certa artificialidade na construção da cena de morte solene e elevada em que o aspecto carnal e baixo da morte seriam transfigurados epicamente. A cena é como o quadro do avô de Hans Castorp, que o protagonista de Mann só tinha visto vestido de vereador uma vez, e mesmo assim considera sua imagem com aquela roupa a verdadeira imagem do avô. Do mesmo modo, Joachim nunca chegou a ser um soldado, mas a cena de morte o converte em um.

Essa ironia final está relacionada, como indica a análise feita em "A mosca e a panela", à segunda analogia da morte de Joachim com a epopeia homérica, esta mais diretamente orientada pela frase de Setembrinni que remete ao canto XI da Odisseia. A interpretação proposta por Pedro Caldas é a de que essa analogia pode ser associada ao subcapítulo "Coisas muito problemáticas", que descreve uma sessão espírita na qual Hans Castorp vê o espectro de seu primo. Porque nessa figura fantasmagórica que aparece posteriormente há uma dissonância em relação à cena idealizada do leito de morte, uma dissonância que me parece revelar justamente o caráter artificial da cena. Em vez do uniforme, Joachim veste uma espécie de túnica, e usa na cabeça uma panela.

Aqui o discurso indireto livre atribui ao personagem o estranhamento: "Mas, coisa estranha! Aquilo Ihe emprestava ares antigos, de lansquenete, e essa marcialidade assentava-lhe bem".

Joachim aparece aqui como uma paródia de guerreiro, um herói fantasiado, o homem comum travestido de guerreiro homérico aos olhos de Hans Castorp. E esse registro cômico é análogo à interferência da mosca na morte do avô, mas num sentido inverso: a panela desconstrói a solenidade da cena de morte elevada, idealizada, assim como a mosca reafirma o sentido baixo e carnal da morte ao pousar no cadáver. Se o sanatório de Davos é uma paródia do mundo dos mortos, Hans Castorp é esse Ulisses que não sabe bem qual sua missão.

\footnotetext{
* Pedro Süssekind é professor adjunto do Departamento de Filosofia da UFF.
} 